\title{
HUBUNGAN ANTARA TINDAKAN VULVA HYGIENE DENGAN PENYEMBUHAN LUKA PERINEUM IBU NIFAS DI BPS TMM DJAMINI DAMUN
}

\author{
Krisnamurti, SST, S.Pd, M.Kes \\ Prodi D-III Kebidanan Universitas PGRI Adi Buana Surabaya
}

\begin{abstract}
ABSTRAK
Angka kejadian infeksi akibat luka perineum pada tahun 2007 sebanyak 45 orang dan 185 orang yang mengalami luka perineum di BPS TMM Djamini Damun Surabaya.

Penelitian ini bertujuan untuk menganalisis hubungan antara tindakan vulva hygiene dengan penyembuhan luka perineum ibu nifas.

Dalam penelitian ini menggunakan penelitian analitik observasional dengan desain cross sectional. Besarnya sampel sebanyak 32 orang dengan luka perineum hari ke 5-7, dengan menggunakan teknik random sampling. Cara pengumpulan data dengan menggunakan lembar check list dan observasi. Data yang terkumpul dianalisis dengan menggunakan uji chi square dengan tingkat kemaknaan $\mathrm{p}<0,05$.

Hasil penelitian menunjukkan bahwa dari 32 responden didapatkan 15 orang melakukan vulva hygiene dengan baik. Dimana 13 orang luka perineumnnya dalam kategori baik. Sedangkan dari 12 orang melakukan kebersihan vulva cukup dimana 15 orang dengan luka perineum dalam kategori sedang. Setelah dilakukan uji chi square ternyata ada hubungan antara vulva hygiene dengan penyembuhan luka perineum ibu nifas. Vulva hygiene yang baik dan benar akan dapat mempercepat proses penyembuhan luka perineumnya.

Dalam hal ini diharapkan seorang bidan sebagai profesi yang paling dekat dengan masyarakat khususnya ibu dan anak agar dapat lebih mempromosikan dan menyebarluaskan informasi melalui penyuluhan tentang melaksanakan vulva hygiene secara baik dan benar para ibu post partum.
\end{abstract}

Kata Kunci : Vulva Hygiene, luka Perineum, Ibu nifas

PENDAHULUAN

Persalinan sering kali

mengakibatkan jalan lahir (Hanifa, 1999).

Perlukaan jalan lahir dapat terjadi oleh

karena kesalahan sewaktu memimpin suatu

persalinan, pada waktu persalinan operatif

melalui vagina seperti ekstraksi cuna, ekstraksi vakum, embriotomi atau trauma

akibat alat-alat yang dipakai. Selain itu perlukaan pada jalan lahir dapat pula terjadi karena memang disengaja seperti pada tindakan episiotomi. Tindakan ini dilakukan untuk mencegah terjadinya robekan perineum yang luas dan dalam 
disertai pinggir yang tidak rata dimana penyembuhan luka akan lambat atau terganggu (Hanifa, 2000).

Meskipun tindakan episiotomi ini dianggap sebagai tindakan operatif yang paling banyak dilakukan (Azrul Azwar, 2000). Namun tindakan episiotomi tidak menjadi penyebab langsung dari munculnya infeksi nifas karena tindakan episiotomi hanya menjadi faktor predisposisi. Karena ketidaktahuan pasien dalam perawatan luka pada jalan lahir dapat mengakibatkan infeksi yang ditandai dengan luka pada perineum menjadi bengkak, merah dan mengeluarkan pus dan bila tidak dilaklukan penanganan yang secara intensif dapat meningkatkan kematian ibu.

Berdasarkan SDKI tahun 2007 didapatkan bahwa kematian ibu (AKI) di Indonesia masih relatif tinggi dibandingkan dengan negara di ASEAN yaitu sebesar 228 per 10.000 kelahiran hidup. Angka tersebut 3-6 kali dari AKI negara ASEAN dari 50 kali AKI Negara dan salah satu disebabkan karena infeksi sekitar 20-30\% (Hanifa, 2005), dimana 25$55 \%$ dari kasus ini disebabkan oleh infeksi jalan lahir (Rustam M, 2003). Menurut Data di BPS TMM DJAMINI DAMUN Surabaya pada tahun 2010 persalinan sebanyak 410 orang yang mengalami luka perineum ada 185 orang dan yang mengalami infeksi 45 orang $(24,3 \%)$. Dari data tersebut menunjukkan bahwa kejadian infeksi bisa terjadi pada persalinan yang disertai luka pada jalan lahir. Oleh karena itu kebersihan daerah vulva dan perineum pada ibu nifas sangat penting untuk menghindari terjadinya infeksi.

\section{METODE}

Penelitian ini menggunakan metode penelitian deskriptif. Pendekatan penelitian yang dilakukan adalah menggunakan cross sectional yang artinya yaitu suatu penelitian untuk mempelajari dinamika korelasi antara faktor-faktor resiko dengan efek, dengan cara 
pendekatan, observasi, atau pengumpulan data sekaligus pada suatu saat (point time approach) artinya tiap subjek penelitian hanya diobservasi sekali saja dan pengukuran dilakukan terhadap status karakteristik atau variabel subjek pada saat pemeriksaan. Waktu dan tempat penelitian dilakukan di BPS TMM Djamini Damun Surabaya pada bulan September - Oktober 2011. Populasi dalam penelitian ini adalah ibu nifas yang melakukan kunjungan ulang / control jahitan dengan luka perineum sebanyak 35 orang di BPS $\mathrm{T}$ MM DJAMINI DAMUN Surabaya. Data yang diperoleh akan diklasifikasikan dan dianalisis secara prosentase dan Korelasi

\section{Product moment.}

\section{HASIL PENELITIAN}

Tindakan perawatan vulva hygiene bisa dilakukan minimal $2 \mathrm{x}$ sehari dan waktu yang lebih baik adalah pada pagi dan sore sebelum mandi, sesudah buang air kecil atau buang air besar 4 jam sekali, terutama pada jahitan perineum tingkat III, tujuan menjaga kebersihan vulva dan sekitarnya membantu dalam penyembuhan luka dan menghindari infeksi. (hamilton, 2004).

Hasil penelitian didapatkan bahwa tingkat pendidikan responden SMA mempunyai pengetahuan yang baik tentang vulva hygiene sebesar 8 orang $(53,3 \%)$, dan yang melakukan dengan cukup sebanyak 6 orang (40\%) dan yang kurang melakukan sebanyak 1 orang $(6,7$ \%). Maka secara garis besar semakin tinggi pendidikan seseorang akan melakukan kebersihan vulva hygiene dengan baik karena orang tersebut lebih mudah menerima informasi dan penyuluhan dari pihak lain.

Luka episiotomi merupakan salah bentuk trauma terjadi pada jaringan perineum ibu setelah melahirkan. Segera setelah dilakukan episiotomi akan terjadi proses inflamasi baik secara vakuler maupun sekuler. Aktivitas ini akan berakhir dalam $2-3$ hari setelah trauma, 
akan lebih cepat dan efektif bila disertai proses vaskularisasi yang adekuat. Proses vaskularisasi yang adekuat akan didukung oleh kondisi luka yang bersih dan baik (Hendersen, 1997).

Berdasarkan hasil penelitian dan hasil analisisnya diperoleh gambaran secara jelas dalam distribusi frekuensi yang menunjukkan bahwa dari 32 responden yang dijadikan obyek penelitian, kesembuhan luka perineum ibu nifas dalam kondisi baik yaitu menutup kering dan tidak ada infeksi sebanyak 13 reponden atau sekitar 40,6\%. Untuk kesembuhan luka perineum dalam kondisi sedang yaitu menutup basah, dengan ada tanda-tanda infeksi dengan jumlah responden sebanyak 15 orang atau sekitar 46, $8 \%$. Dan pada responden yang luka perineumnya dalam kondisi buruk yaitu membuka basah dan terjadi infeksi sebanyak 4 orang atau sekitar 12,5\%. Sehingga secara garis besar penyembuhan luka perineum ibu nifas pada responden di BPS TMM Djamini Damun Surabaya adalah dalam kondisi baik sebanyak 13 orang atau sekitar 40,6\% dan yang sedang sebanyak 15 orang atau sekitar $46,8 \%$ yang berarti secara total dari 32 responden mengalami kesembuhan luka perineum.

Kebersihan vulva berperan proses luka yang baik oleh karena itu harus memperhatikan teknik atau cara kebersihan vulva yang baik dan benar, frekuensi dan bahan yang digunakan. Sehingga proses efitelisasi juga berjalan dengan baik untuk kesembuhan luka, proses ini terjadi dalam 40 jam setelah terjadinya trauma menghasilkan jaringan ini sangat tipis dan tidak kokoh sehingga rentan terhadap trauma. Jaringan ini terus berlangsung terjadi trauma

\section{Hasil analisis dengan Korelasi}

Product Moment menunjukkan nilai koefisien korelasi $r_{x y}=0,707$ sehingga nilai $r_{x y}$ lebih besar dari Nilai $r_{\text {tabel }} \quad(0$ ,707 > 0,349) maka berarti menolak Ho dan menerima Hi dengan demikian hipotesis penelitian "Ada Hubungan 
Antara Tindakan Vulva Hygiene Dengan

Penyembuhan Luka Perineum Ibu Nifas Di

BPS TMM Djamini Damun Surabaya" terbukti kebenarannya.

Secara konseptual hal ini dapat dipahami mengenai kebersihan vulva baik dan benar, sesuai prosedur dan memperhatikan aspek sterilitas sehingga akan mempercepat proses pemuliha jaringan. Pemulihan jaringan ini sering disebut dengan penyembuhan luka. Frekuensi kebersihan vulva yang sesuai juga akan menentukan proses penyembuhan luka. Responden dengan kebersihan vulva yang baik akan dapat memutuskan mata rantai perkembangbiakan mikoroorganisme disekitar luka sehingga proses penyembuhan luka lebih baik. Namun demikian frekuensi kebersihan vulva juga disarankan baik berlebihan, dikhawatirkan apabila berlebihan akan mengakibatkan iritasi sehingga membuka lingkungan yang subur untuk perkembangan mikroorganisme (Cristina, 1998).

\section{DAFTAR PUSTAKA}

Arikunto, Suharsimi (1998). Prosedur Penelitian Suatu Pendekatan Praktek. Edisi Revisi IV. Rineka Cipta. Jakarta.

Cristina (1998). Perawatan Kebidanan Jilid III. Bharta Karya Sastra. Jakarta.

Hamilton, PM (1995). Dasar-Dasar Perawatan Maternitas. EGC. Jakarta.

Hanifa, W (1999). Ilmu Kebidanan. YBPSP. Jakarta

Henderson, MA (1997). Ilmu Bedah untuk Perawat. Yayasan Essential. Yogyakarta.

Manuaba, IBG (1998). Ilmu Kebidanan, Ilmu Kandungan dan Keluarga Berencana. EGC. Jakarta 
Morisson, MJ (2004). Manajemen Luka.

EGC. Jakarta

Notoatmodjo, Soekidjo (2005).

Metodologi Penelitian

Kesehatan. Rhineka Cipta

Jakarta.

Nursalam dan Pariani (2001). Metodelogi

Riset Perawat. CV. Pioner

Jaya. Jakarta.

Prawirohardjo, S (2000). Ilmu bedah kebidanan. YBPSP. Jakarta.

Rustam, Mochtar (1998). Obstetri Fisiologi Jilid I Edisi I.

EGC. Jakarta
Syaifuddin, AB (2002). Buku Acuan Nasional Kesehatan

Maternal dan Neonatal. JNP KKR-POGI. Jakarta

Sastroasmoro, S (1995). Dasar-Dasar Metodelogi Penelitian Klinis. Bina Rupa Aksara. Jakarta.

Sheldon, H (1999). Perawatan Modern untuk Kesehatan Wanita. TV. Pioner. Jakarta. 